\title{
Comments on an indirect tensile test on concrete cylinders*
}

\author{
by P. J. F. Wright, B.Sc.
}

\section{Contribution by Professor R. H. Evans}

I have taken a particular interest in methods of testing concrete in tension and have carried out experiments on the tensile strength of concrete using (a) briquettes of varying dimensions, (b) cylinders of different diameters, (c) modulus of rupture. Some of these results have appeared in a paper ${ }^{(1)} \dagger$ from which it will be seen that it is extremely difficult to load any tension specimen axially, and that generally the results obtained in the tensile testing of concrete are low, owing to the great difficulty of avoiding eccentricity of loading. The author's attention was first drawn to the cylinder method of testing in 1952 by Dr M. Uchiyama of Japan. Mr Wright, in his paper, infers that the test has been introduced by Fernando Carneiro of Brazil in 1947, but this does not appear to be correct. It seems that the method was proposed in the first place in 1942 by $\mathrm{Mr} \mathrm{T}$. Akazawa, Chief Engineer of the Iwaki Concrete Company, Japan, and the reliability of the method was established by Dr Uchiyama in 1944. By 1951 this method of testing concrete in tension had been adopted as a standard test by the Japanese Industrial Standard (J.I.S.) and by the Japanese Society of Civil Engineering. The method is again referred to in the paper ${ }^{(2)}$ presented by $\mathrm{J}$. Vuorinen to the Fourth Congress on Large Dams at New Delhi in 1951 .

There follows a translation of the Japanese Industrial Standard, published in 1951.

\section{JAPANESE INDUSTRIAL STANDARD J.I.S. A.1113 (1951)}

Standard method of test for tensile strength of concrete.

1 Scope

This method covers the procedure for tension tests of concrete cylinders.

2 Apparatus

2.1 Forms shall be as specified in J.I.S. A.1108 (Standard method of - test for compressive strength of concrete). In assembling the moulds, special care shall be taken to make the sides of cylinders in correct forms.

2.2 Rodding bar shall be as specified in J.I.S. A.1108.

\section{Test specimens}

3.1 The minimum size of specimens shall be more than four times the maximum size of coarse aggregate.

3.2 The length of specimens shall be larger than the diameter.

Note 1. The length of specimens shall be determined according to the size of loading plates of the testing machine.

3.3 Concrete shall be filled in layers of almost equal thickness, which are between 7.5 and $10 \mathrm{~cm}$.

Each layer shall be rodded following J.I.S. A.1108. After filling the concrete, the surface shall be levelled with a trowel.

Note 2. The thickness of each layer shall be $10 \mathrm{~cm}$ when the length of specimens is either 30 or $20 \mathrm{~cm}$, and $7.5 \mathrm{~cm}$ when the length of specimen is $15 \mathrm{~cm}$.

4 Curing

Test specimens shall be removed from the moulds and cured in accordance with J.I.S. A.1108.

5 Test

5.1 Tension tests shall be made as soon as practicable after removal from the curing room. Specimens shall be tested in a moist condition.

5.2 The diameter of the specimen, $d$, in the loading direction shall be measured to the nearest $\frac{1}{4 m}$.

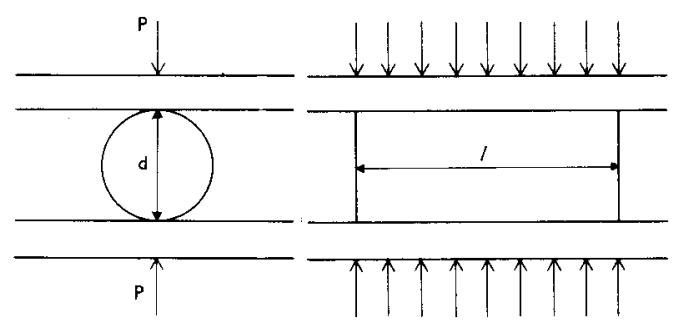

5.3 Specimens shall be placéd laterally without eccentricities. The contact of loading plates with the specimen shall be as intimate as possible so as to allow no gap between the plates and the specimen. 
Note 3. Sometimes the gap of about $0 \cdot 1 \mathrm{~mm}$ between specimen and loading plates will cause the specimen to exhibit partial failure due to eccentric loading.

5.4 After placing the specimens correctly, load shall be applied in the vertical direction.

Both loading plates shall be kept parallel during testing. The load shall be applied at a constant rate not more than $5 \mathrm{~kg} / \mathrm{cm}^{2}$ per minute. During the application of the first half of the maximum load a higher rate of loading shall be permitted.

5.5 Average length $l$ shall be determined to the nearest $\frac{1}{4} \mathrm{~mm}$ in the plane of failure.

\section{Calculation}

The tensile strength of the specimen shall be calculated by the following formula

$$
\sigma=\frac{2 P}{d l}
$$

where $\sigma=$ tensile strength in $\mathrm{kg} / \mathrm{cm}^{2}$;

$$
\begin{aligned}
P= & \text { maximum load (shown by testing } \\
& \text { machine) in } \mathrm{kg} ; \\
d= & \text { diameter in } \mathrm{cm} ; \\
l= & \text { length in } \mathrm{cm} .
\end{aligned}
$$

It will be noted that the clauses specified in Japan are in general agreement with the results of the tests obtained by $\mathrm{Mr}$ Wright at the Road Research Laboratory. Dr Uchiyama and the Japanese Industrial Standard do specify that the length of the specimen should be larger than the diameter and, although this point has not been emphasized by $\mathrm{Mr}$ Wright, it would be interesting to have his comments upon it.

The elastic theory relative to stresses in a circular diameter has been worked out by Timoshenko in his book entitled " Theory of Elasticity" ${ }^{\prime 3\}}$ and by Prescott in his book entitled "Applied Elasticity" (4), and it is not necessary to refer to the actual method of calculation. It is very satisfactory to note that the standard deviation and the coefficient of variation in $\mathrm{Mr}$ Wright's experiments are substantially in agreement with those observed by Dr Uchiyama, and one is led to believe that this simple way of testing concrete in tension has great possibilities.

It is hoped that Mr Wright will continue the work to examine the influence of the size of the aggregate, to determine more precisely the relationship between the length of the specimen and its diameter, and to acquire more data about the use of both soft and hard packing materials.

\section{REFERENCES}

(1) EVANS, R. H. Extensibility and modulus of rupture of concrete. The Structural Engineer. December 1946. Vol. 24, No. 12. pp. 636-659.

(2) VUORINEN, J. Some tests on the effect of air entrainment on the tensile strength and watertightness of concrete by making use of the splitting test method. Transactions of the Fourth Congress on Large Dams. Vol. 3. p. 109.

(3) TIMOSHENKo, s. Theory of Elasticity. McGraw-Hill Book Company, New York. 1st edition. 1934, pp. xvi, 416 .

(4) Prescott, J. Applied Elasticity. Longmans, Green \& Co., London. Ist edition. 1924. pp. 666.

\section{Reply by the author}

The author is grateful to Professor Evans for his interesting comments on the indirect tensile test and is particularly interested to note that the test was used in Japan in 1942. It seems likely that the test was introduced independently in Brazil and in Japan as Carneiro states that it arose from observing the splitting of concrete rollers which were being used in the moving of a building. In some countries the test has become known as the "Brazilian Test" and the Japanese origin does not seem to have been generally acknowledged.

It would be interesting to know the reason for the requirement in the Japanese Industrial Standard that the length of the specimen should be greater than the diameter. The work done at the Road Research Laboratory, although not exhaustive, suggested that such a limitation was not necessary. As shown in Table 4 of the paper, 6 in. diameter cylinders were used 12 in., 6 in. and 3 in. long, and in fact the shorter ones were easier to prepare and test than the long ones. The average strength did not seem to be affected by the ratio of length to diameter although the variation probably increases continuously as the length is reduced. This, however, probably depends more on the over-all size of the specimen, possibly on the area over which failure occurs, than on the ratio of length to diameter.

It was particularly valuable to have Professor Evans's English translation of the Japanese Industrial Standard. It is bound to become more widely known as a result. 